\title{
Limiting properties in the characterisation of mixed recycled aggregates for use in the manufacture of concrete
}

\author{
F. Agrela ${ }^{\mathrm{a}, *}$, M. Sánchez de Juan ${ }^{\mathrm{b}}$, J. Ayuso ${ }^{\mathrm{a}}$, V.L. Geraldes ${ }^{\mathrm{b}}$, J.R. Jiménez ${ }^{\mathrm{a}}$
}

\begin{abstract}
A B S T R A C T
Recycling of construction and demolition waste (CDW) has become a widespread concern in Spain for the last years, as a way to preserve natural resources and achieve a better control of waste disposal sites. Specific applications which make use of mixed recycled aggregates are of great importance, as this types of aggregates constitute the majority of the total production. Structural and non-structural concrete is one of the possible applications, being this the main goal of our study.

This paper presents a study on the physical and chemical characteristics of mixed recycled aggregates which have been obtained from different CDW treatment plants of Spain. Correlations between the different properties were investigated in order to find criterions of acceptance for recycled aggregates to be used in concrete.

The comparison between the properties offers the possibility of pre-selecting a great quantity of mixed recycled aggregates, these being suitable for either structural and non-structural concrete. The determination of water absorption and the gypsum content are good indicators in order to evaluate the quality of the mixed recycled aggregates for its application in the production of concrete.
\end{abstract}

\section{Introduction}

During the last few years, various properties of recycled aggregates (RA) have been investigated with the aim of using them in concrete manufacture. Nowadays, the use of these materials is being promoted by means of the development of international standardization, such as EHE-08 [1], BS-8500 [2], RILEM [3], DIN 4226.100 [4], in order to benefit the environment. This benefit includes a reduction of the amount of natural aggregates extracted from quarries and river-beds, which are used in concrete production and other applications as well.

These recycled aggregates which are often used in the production of concrete are named as recycled concrete aggregates, mainly obtained from crushed concrete (corresponding to type II according to RILEM classification [3]).

In the Mediterranean countries, such as Spain, Portugal, Italy or Greece, the architectural elements mostly used in buildings often include ceramic elements combined with mortar and concrete, including sometimes gypsum in interior faces [5]. Therefore it is not unusual to find a large quantity of ceramic particles mixed with concrete - usually designated as mixed recycled aggregates - in recycled aggregates processed from construction and demolition waste [6]. Furthermore, recycled aggregates also include small amounts of other materials, like gypsum and asphalt particles. These are considered as impurities due to their negative effect on concrete properties [7-9]. The content of these impurities depends on the origin of waste material as well as on the process carried out at the recycling plant, and it can range from $0 \%$ to $35 \%$ for asphalt particles [8], to $0-5 \%$ for gypsum $[7,8]$.

Spanish regulation [1] allows the use of coarse RCA - recycled concrete aggregates - in concretes, excluding the use of mixed recycled aggregates, even in non-structural concretes.

The use of the fine fraction is excluded too, because of its higher absorption and of the presence of impurities, that generally lead to worse physical properties in the recycled concrete, such as water absorption and carbonation. On the contrary, the mechanical behaviour is quite heterogeneous, since both decrease and increase of the compressive strength is observed, as demonstrated in the bibliographic studies [10].

Only a few applications, and only in non-structural concrete, have been made by using mixed recycled aggregates [5,11-13], mainly due either to the lack of international regulations and to the lower quality of the recycled aggregates in comparison to natural ones, which involves a larger deeper control in order 
Table 1

Characterisation tests.

\begin{tabular}{ll}
\hline Test & Method \\
\hline Composition of the recycled aggregate & UNE-EN 933-11 \\
Absorption and density & \\
(24 h and 10 min) & UNE-EN 1097-6 \\
Sulphur content and soluble sulphates & UNE-EN 1744-1 \\
\hline
\end{tabular}

to guarantee its conformity, such as an adequate treatment process and the control of the waste in the unit plant entrance.

In Spain, mixed recycled aggregates are usually employed in road sub-bases and rural paths. This study is particularly focused on mixed recycled aggregates obtained from the C\&D wastes treatment plants of Spain. The main objective was to correlate the fractionated components of the recycled aggregates, with their characterisation properties, namely water absorption, density, sulphate and sulphur contents.

A classification of recycled aggregate is expected to be established that distinguishes between the different mixed recycled aggregates quality coming from the recycling plants, in order to use them in the most accurate applications.

This project has been carried out by the following institutions: UCO Universidad de Córdoba, CEDEX Centro de Experimentación de Obras Pûblicas, AIDICO Instituto Tecnológico de la Construcción and Fundación LABEIN (Spain), with the support of the company SACYR.

\section{Materials and experiments}

\subsection{Materials}

A study of a total of 35 recycled coarse aggregates with different contents of ceramic particles and concrete, which had been obtained from 13 C\&D wastes recycling plants of different parts of Spain, was carried out in order to establish criterions of acceptance or rejection of recycled aggregates in the recycling plant for their use in concrete.

The main objectives of our study are to obtain the composition of coarse recycled aggregate and its correlation with absorption, density and soluble sulphates content.

In order to do so, the aggregates were divided in three groups, depending on their proportions of particles coming from concrete (loose aggregates or aggregates with attached mortar), and those coming from ceramic elements. Therefore, basing on the different international regulations $[8,14]$, the following limits of concrete and ceramic particles contents in weight were established for each of the three groups:

- Concrete recycled aggregate - CRA - ceramic content $\leqslant 10 \%$ and concrete content $\geqslant 90 \%$.

- Mixed recycled aggregate - MixRA - ceramic content $\leqslant 30 \%$ and $>0 \%$, and concrete content $\geqslant 70 \%$ and $<90 \%$.

- Ceramic recycled aggregates - CerRA - ceramic content $>30 \%$ and concrete content $<70 \%$.

\subsection{Laboratory testing}

For recycled aggregate characterisation, following tests were carried out: composition tests, water absorption, density, sulphur content and acid soluble sulphates in, were realized (Table 1 ). These tests correspond to the most unfavourable properties of mixed recycled aggregates. Studies of the component were

Table 2

Results of properties of recycled materials.

\begin{tabular}{|c|c|c|c|c|c|c|c|c|c|c|c|}
\hline & \multicolumn{5}{|c|}{ Constituents of coarse recycled aggregate } & \multicolumn{2}{|c|}{ Absorption (\%) } & \multicolumn{2}{|c|}{ SSD density $\left(\mathrm{mg} / \mathrm{m}^{3}\right)$} & \multirow[t]{2}{*}{ Soluble sulphate $\left(\% \mathrm{SO}_{3}\right)$} & \multirow[t]{2}{*}{ Sulphur content (\%S) } \\
\hline & Concrete & Brick & Asphalt & Gypsum & Glass & $10 \mathrm{~min}$ & $24 \mathrm{~h}$ & $10 \mathrm{~min}$ & $24 \mathrm{~h}$ & & \\
\hline CRA1 & 97.7 & 1.9 & 0.3 & 0 & 0 & 4.23 & 5.2 & 2.34 & 2.34 & 0.33 & 0.22 \\
\hline CRA2 & 93.7 & 3.4 & 2.9 & 0 & 0 & & 5.1 & & 2.41 & 0.42 & 0.27 \\
\hline CRA3 & 91.5 & 7.2 & 1.1 & 0 & 0.1 & 6.7 & 7.3 & 2.35 & 2.35 & 0.44 & 0.26 \\
\hline CRA4 & 91.1 & 4.1 & 4.6 & 0.1 & 0.1 & & 5.9 & & 2.43 & 0.38 & 0.25 \\
\hline CRA5 & 90.5 & 7.2 & 1.2 & 1 & 0 & - & 3.6 & - & 2.47 & 0.44 & 0.26 \\
\hline MixRA1 & 88.9 & 6 & 5 & 0.1 & 0 & & 4.9 & & 2.4 & 0.22 & 0.15 \\
\hline MixRA2 & 88.3 & 9.8 & 1.6 & 0.1 & 0.2 & - & 2.1 & - & 2.58 & 0.37 & 0.15 \\
\hline MixRA3 & 84.42 & 14.22 & 0.34 & 0.5 & 0.3 & 6.71 & 7.4 & 2.33 & 2.34 & 0.19 & 0.2 \\
\hline MixRA4 & 83.8 & 7.22 & 11.1 & 0 & 0 & - & 3.46 & - & 2.48 & 0.04 & 0.12 \\
\hline MixRA5 & 80.1 & 19 & 0.7 & 0 & 0 & - & 5.7 & - & 2.36 & 1.41 & 0.67 \\
\hline MixRA6 & 80 & 15 & 0 & 0 & 0.01 & 8.2 & 7.8 & 2.32 & 2.3 & 0.23 & 0.3 \\
\hline MixRA7 & 78.84 & 19.33 & 0.3 & 0.42 & 0.29 & 7.45 & 8.79 & 2.31 & 2.24 & 0.15 & 0.21 \\
\hline MixRA8 & 78.74 & 14.48 & 4.55 & 2.1 & 0 & 6.3 & 8.1 & 2.28 & 2.29 & & 0.57 \\
\hline MixRA9 & 78.7 & 12.7 & 3.8 & 2.7 & 1.53 & - & 4.7 & - & 2.44 & 1.23 & 0.46 \\
\hline MixRA10 & 78.7 & 16.9 & 6.9 & 0.1 & 0 & - & 5.2 & - & 2.4 & 0.56 & 0.3 \\
\hline MixRA11 & 78.47 & 14.74 & 4.49 & 1.01 & 0.34 & 5.3 & 7 & 2.26 & 2.26 & & 0.76 \\
\hline MixRA12 & 78 & 18.8 & 0.65 & 1.1 & 0.55 & 8.56 & 8.68 & 2.28 & 2.29 & 0.3 & 0.35 \\
\hline MixRA13 & 76.6 & 20.6 & 1 & 0.1 & 0.1 & 5.9 & 7.3 & 2.3 & 2.27 & 0.39 & 0.23 \\
\hline MixRA14 & 72.5 & 19 & 3.6 & 3.2 & 1.51 & - & 6.3 & - & 2.22 & & 0.93 \\
\hline MixRA15 & 71.7 & 27.8 & 0 & 0.46 & 0 & - & 6.5 & - & 2.33 & 1.71 & 0.77 \\
\hline MixRA16 & 71.5 & 16.4 & 11.7 & 0.2 & 0 & - & 5.5 & - & 2.34 & 0.66 & 0.45 \\
\hline MixRA17 & 70.44 & 22.21 & 4.03 & 2.63 & 0.15 & 5.8 & 8.8 & 2.3 & 2.27 & & 0.79 \\
\hline MixRA18 & 70.3 & 28.9 & 0.2 & 0.15 & 0.43 & - & 6.6 & - & 2.32 & & 0.68 \\
\hline MixRA19 & 70.01 & 12.9 & 16.7 & 0 & 0 & - & 3.79 & - & 2.35 & 0.37 & 0.15 \\
\hline CerRA1 & 65.08 & 30.08 & 2.8 & 1.8 & 0.17 & 5.04 & 7.21 & 2.4 & 2.23 & & 0.68 \\
\hline CerRA2 & 59.4 & 40 & 2.2 & 0 & 1.3 & - & 7.5 & - & 2.27 & & 0.8 \\
\hline CerRA3 & 58 & 33 & 0 & 4 & 0.6 & 10.5 & 12.2 & 2.17 & 2.1 & 0.56 & 0.27 \\
\hline CerRA4 & 55.6 & 36.9 & 5.1 & 2.7 & 0 & - & 8.85 & - & 2.39 & 1.07 & 0.52 \\
\hline CerRA5 & 46.5 & 39.3 & 6.9 & 9.9 & 0.75 & - & 12.5 & - & 2.06 & 4.45 & \\
\hline CerRA6 & 45.69 & 51.57 & 0.29 & 1.66 & 0.28 & 12.74 & 13.28 & 2.1 & 2.12 & 1.71 & 1.9 \\
\hline CerRA7 & 45.3 & 52.59 & 0.12 & 1.32 & 0.27 & 11.94 & 13.75 & 2.12 & 2.11 & 1.57 & 1.24 \\
\hline CerRA8 & 44.89 & 53.11 & 0.17 & 1.15 & 0.42 & 12.72 & 14.29 & 2.07 & 2.06 & 0.68 & 0.87 \\
\hline CerRA9 & 44.14 & 53.9 & 0.22 & 1.2 & 0.34 & 11.46 & 14.02 & 2.12 & 2.09 & 1.23 & 1.52 \\
\hline CerRA10 & 38 & 49.5 & 5.9 & 3 & 2.3 & - & 10.3 & - & 2.15 & 0.89 & 0.77 \\
\hline CerRA11 & 36.38 & 47.76 & 4.73 & 7.5 & 0.3 & - & 14.36 & - & 2.15 & & \\
\hline Medium value $C R A$ & 92.90 & 4.76 & 2.02 & 0.22 & 0.04 & 5.47 & 5.42 & 2.35 & 2.40 & 0.40 & 0.25 \\
\hline Medium value MixRA & 77.90 & 16.63 & 4.03 & 0.78 & 0.28 & 6.78 & 6.24 & 2.30 & 2.34 & 0.56 & 0.43 \\
\hline Medium value CerRA & 49.00 & 44.34 & 2.58 & 3.11 & 0.61 & 10.73 & 11.66 & 2.16 & 2.16 & 1.52 & 0,95 \\
\hline
\end{tabular}

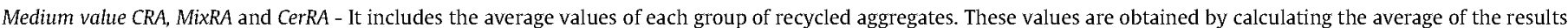
shown in each column of the table, and in each group of recycled aggregates, CRA, MixRA and CerRA. 


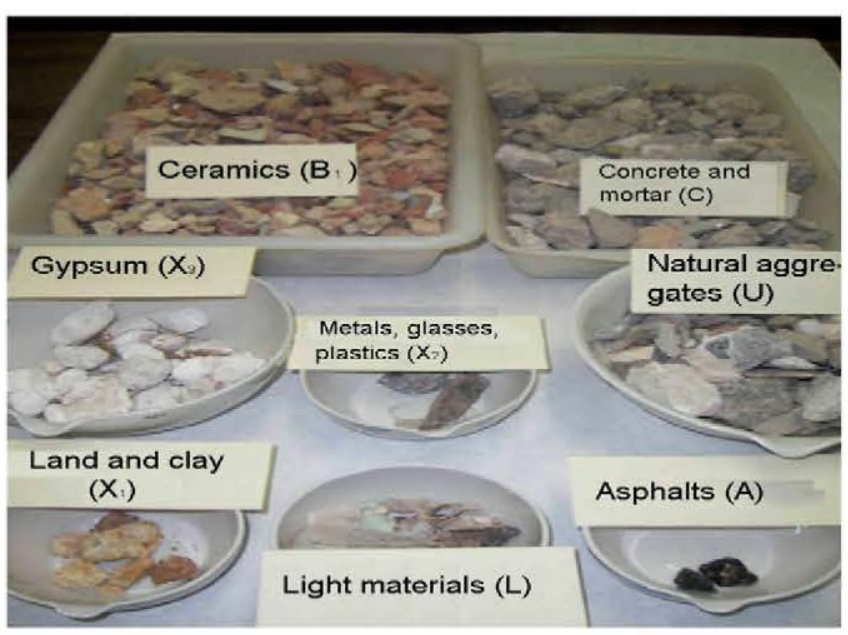

Fig. 1. Test of composition.

done following the procedure UNE-EN-933-11 - "Test for the classification of recycled aggregates according to their composition" [15]. In Table 2, the 35 materials which where the object of the study have been classified into the three groups described above, according to their composition (Fig. 1). The groups of components specified in that procedure are particles from concrete, ceramic, asphalt, glass and others (gypsum, metals, plastic, clay lumps and lightweight materials, among others).

Water absorption and saturated surface dry density (SSD) are two decisive properties that define the quality of aggregate. The high absorption of mixed recycled aggregates must be taken into consideration in concrete mixing, due to the fact that part of the water added in the mix will fulfil the accessible pores of recycled aggregates, thus reducing concrete workability, as well. This effect can be made up through a process of aggregate pre-soaking, in which case SSD density must be taken into account during the process of concrete mixing.

Furthermore, mixed recycled aggregates usually present a high gypsum content, since the original materials usually come from building construction. Sulphates content present in gypsum must also be controlled [17], because they can lead to expansions in concrete.

All tests were carried out in the coarse particle size of the recycled aggregate $(4 / 31.5 \mathrm{~mm})$, except for the composition test, which was made on $8 / 31.5 \mathrm{~mm}$ particle size, according to UNE-EN 933-11 [15].

Regarding water absorption test, the sample was immersed in water during $24 \mathrm{~h}$, according to UNE-EN 1097-6 [16].

In addition to these absorption tests measured during a 24-h-period, in those tests on recycled aggregate for its application in concrete, it is particularly useful to determine the water absorption during a 10 -min-period, so as to estimate the amount of water absorbed by the aggregate during the mixing of concrete, when in dry state.

\section{Results}

Table 2 shows the results of the properties that have been tested. According to the classification described in Section 2.1, the recycled aggregates tested include five aggregates belong to group CRA, 19 aggregates belonging to MixRA group, and other 11 ones belonging to CerRA group. The average values of each group of materials studied are indicated at the bottom of Table 2 .

As it can be observed in Table 2, there is a wide variation in aggregates composition. The percentage of concrete content (natural aggregate and attached mortar) ranges between $36.4 \%$ and $97.7 \%$, whereas ceramic particles content ranges between $1.9 \%$ and $53.9 \%$. Asphalt content was lower than $5 \%$, and glass content was lower than $1 \%$ in most cases. Nevertheless, some samples contained a higher percentage of asphalt particles, one of them reaching $16.9 \%$. According to different studies [12,13], a high content of asphalt leads to a decrease of the compressive strength, reaching a decrease that oscillates between $16 \%$ and $37 \%$, when the recycled concrete incorporates up to a $20 \%$ of asphalt.

These values might seem excessive for application in concrete according to the regulations consulted $[2,3,14,22]$. Hence, the treatment plants should take a more detailed control on materials in origin, so that their content can be limited.

Table 3 shows the averages values for an interval of $95 \%$ of reliability, as well as the extreme values of density and absorption during $24 \mathrm{~h}$, for each of the three groups studied. It can be noticed that the average density for an interval of $95 \%$ of reliability in the CRA group $\left(2.40 \mathrm{~kg} / \mathrm{dm}^{3}\right)$ is $2.5 \%$ higher than the average density in the MixRA group $\left(2.34 \mathrm{~kg} / \mathrm{dm}^{3}\right)$. What's more, this one is $8.3 \%$ higher than the average value of the CerRA group $\left(2.16 \mathrm{~kg} / \mathrm{dm}^{3}\right)$. A decrease of the values of density in the third group is also observed, obtaining an average decrease of $10 \%$ in the recycled concrete aggregate, due to the lower density of the ceramic particles.

On the other hand, there are significant variations in the values of absorption as well. In the CRA and MixRA groups, the average values of absorption are considerably close, between $3.7 \%$ and $7.1 \%$ in CRA and between $5.3 \%$ and $7.2 \%$ in MixRA, for a confident interval of $95 \%$. In the CerRA group, the absorption values are very superior to those obtained for the other two groups, ranging from $9.9 \%$ to $13.5 \%$ in an interval of $95 \%$ of reliability, and obtaining $11.66 \%$ as an average value.

These values are quite similar to those obtained in different studies consulted in bibliography [18-21].

Thus, in light of the results obtained, it has clearly been demonstrated that a high content of ceramic particles leads to an increase of the absorption and a decrease of the recycled aggregate density, due to the high absorption and the low density of ceramic aggregate.

\section{Correlations and discussion}

Correlations between different properties of recycled aggregate were evaluated.

\subsection{Correlations between concrete and ceramic particles contents with absorption and density}

As it can be seen in Table 2, two major constituents of recycled aggregates are concrete and brick, as they both together make up between $82.7 \%$ and $99.6 \%$ of the whole material. As a consequence, the two of them are closely related, and a high content of concrete particles involves a low content of ceramic particles, as it is illustrated in Fig. 2.

According to the regression obtained in Fig. 2, on average, there is a $95 \%$ proportion of particles from concrete and ceramic particles. Content of ceramic particles has a clear influence on water absorption and SSD density, thus obtaining a good correlation between these parameters (Figs. 3 and 4). Correlation coefficients between ceramic content and absorption and SSD density are 0.74 and 0.65 , respectively.

Table 3

Range of density and water absorption for different types of recycled aggregates.

\begin{tabular}{|c|c|c|c|c|c|c|}
\hline & \multirow{2}{*}{ Ceramic - B (\%) } & \multirow{2}{*}{ Concrete - C (\%) } & \multicolumn{2}{|l|}{ SSD density $\left(\mathrm{kg} / \mathrm{dm}^{3}\right)$} & \multicolumn{2}{|l|}{ Water absorption $24 \mathrm{~h}(\%)$} \\
\hline & & & $95 \%$ Int confianza valor Medio & Valores extremos & $95 \%$ Int confianza valor Medio & Valores extremos \\
\hline CRA & $\leqslant 10$ & $\geqslant 90$ & $2.40+-0.07$ & $2.34-2.47$ & $5.42+-1.7$ & $3.6-7.3$ \\
\hline MixRA & $\leqslant 30$ & $\geqslant 70$ & $2.34+-0.04$ & $2.22-2.58$ & $6.24+-0.9$ & $2.1-8.79$ \\
\hline CerRA & $>30$ & $<70$ & $2.16+-0.04$ & $2.06-2.39$ & $11.66+-1.8$ & $7.21-14.36$ \\
\hline
\end{tabular}




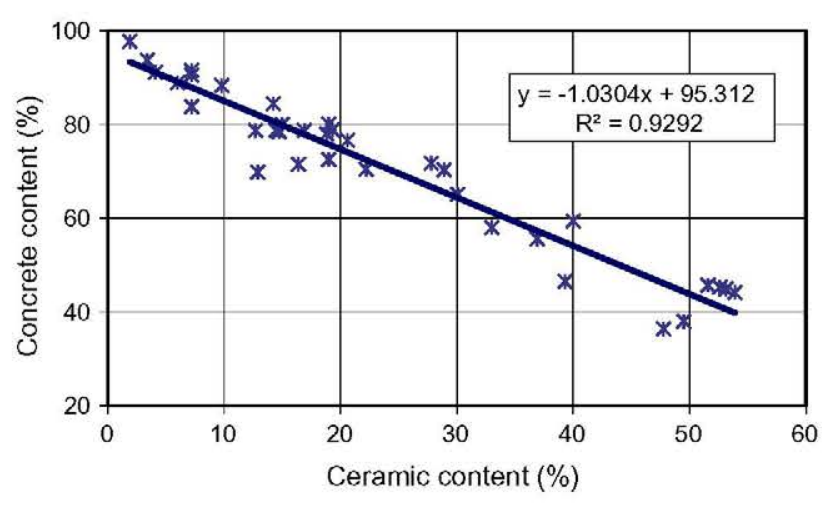

Fig. 2. Correlation between concrete and ceramic contents.

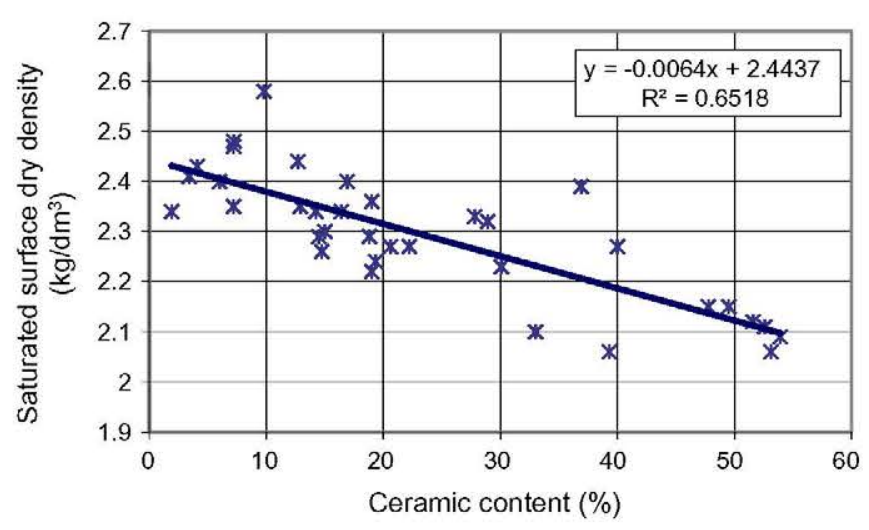

Fig. 3. Relation between ceramic content and SSD density.

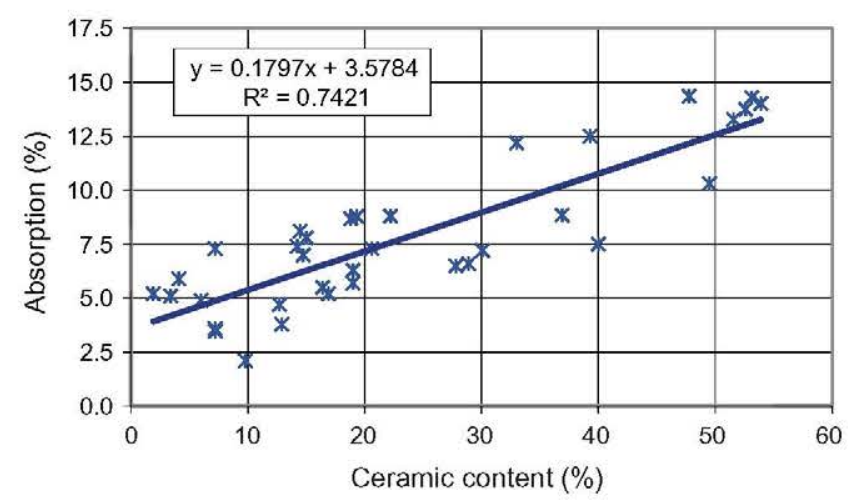

Fig. 4. Relation between ceramic content and water absorption.

If we compare concrete particles content with absorption and density of recycled aggregate, we can appreciate that the higher is the concrete content, the higher is its density and the lower its absorption (Figs. 5 and 6). Correlation coefficients between concrete content and absorption and SSD density ranges from 0.70 to 0.65 , respectively.

From correlations obtained in Figs. 5 and 6, we can define the normal range for density and absorption of each recycled aggregate category, as it is shown in Table 3.

\subsection{Correlation between water absorption and density of recycled aggregate}

Water absorption of coarse recycled aggregates ranges from $2.1 \%$ to $14.36 \%$, while saturated surface dry density ranges from

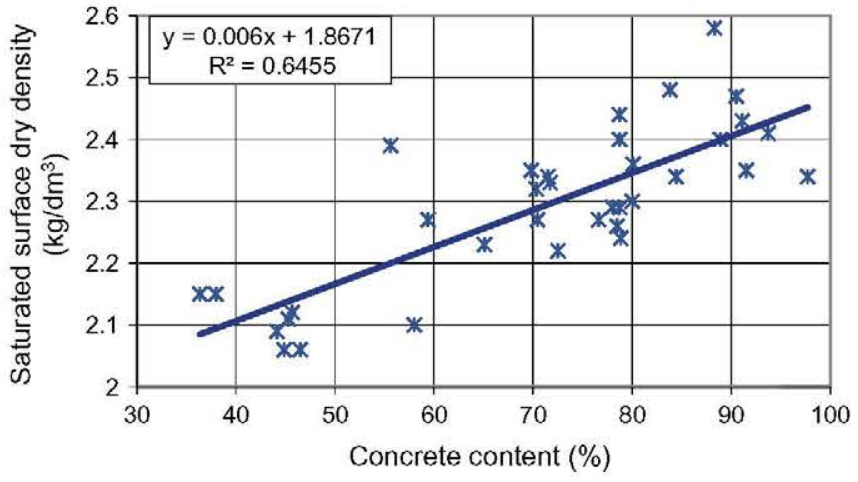

Fig. 5. Correlation between concrete content and SSD density.

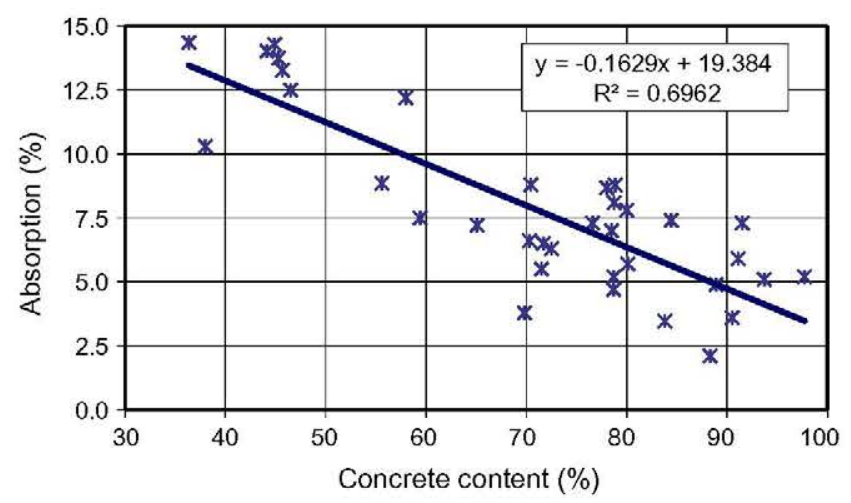

Fig. 6. Correlation between concrete content and water absorption.

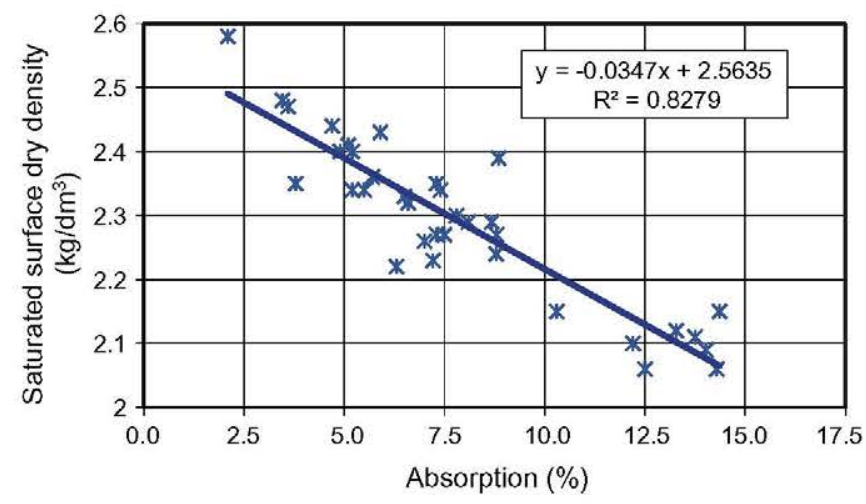

Fig. 7. Correlation between absorption and SSD density of recycled aggregates.

2.06 to $2.58 \mathrm{~kg} / \mathrm{dm}^{3}$. Both parameters depend essentially on recycled aggregate constituents - mainly on brick or ceramic particles contents and on concrete. Fig. 7 shows that there is a good correlation between water absorption and density $\left(R^{2}=0.83\right)$.

4.3. Correlation between absorption and density making the saturation in $24 \mathrm{~h}$ and $10 \mathrm{~min}$

In addition to the test consisting on a 24-h-water absorption, in recycled aggregates it is also useful to make a 10 -min absorption test afterwards, in order to estimate the amount of water that will be absorbed by recycled aggregate during concrete mixing, when this recycled aggregate is used in dry conditions.

of the 35 samples analysed, 16 were tested for determination, saturating them during $10 \mathrm{~min}$ and $24 \mathrm{~h}$, according to UNE-EN 


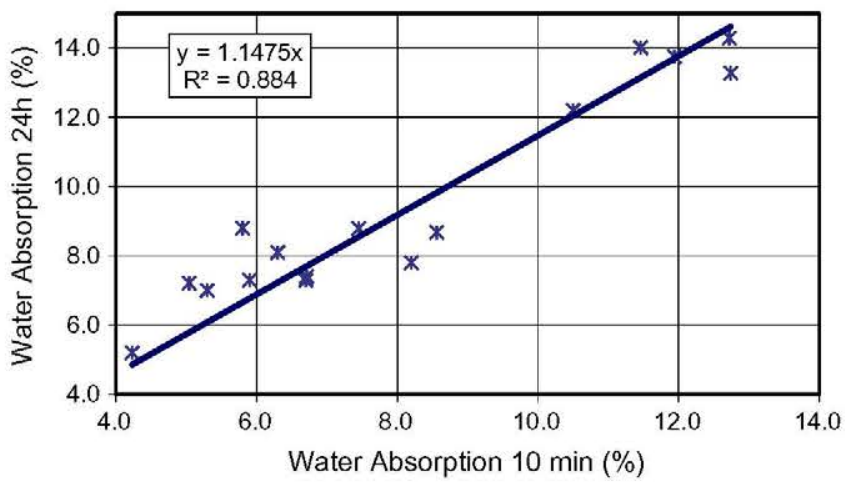

Fig. 8. Correlation between water absorption after $10 \mathrm{~min}$ and $24 \mathrm{~h}$ of sample saturation.

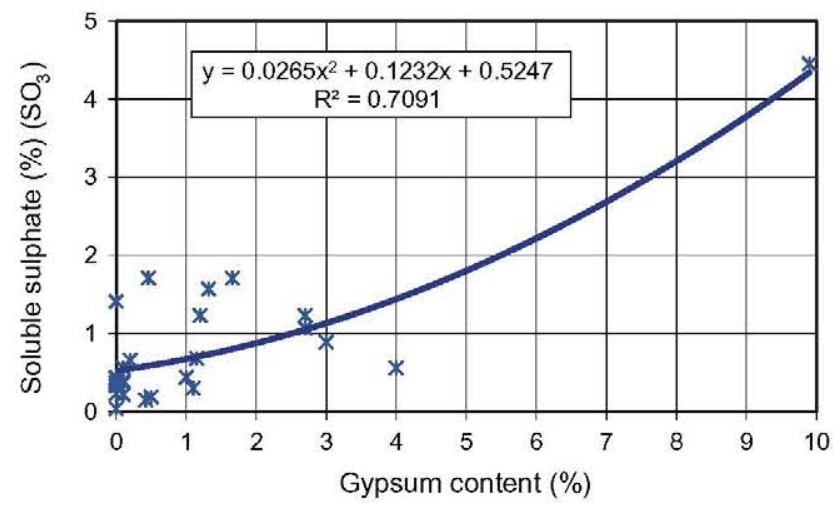

Fig. 9. Correlation between gypsum content and soluble sulphates.

1097-1 [5]. The main objective of this test was to establish a correlation between both parameters. Results are shown in Fig. 8.

It can be seen that these results adjust themselves at a linear regression with a correlation coefficient of $R^{2}=0.88$. According to the results obtained, a 10 -min water absorption reaches $85 \%$ of a 24-h water absorption. As a consequence, the time for water absorption determination could be reduced to $10 \mathrm{~min}$, and a correction factor of $1 / 0.85$ could be applied in order to obtain the same water absorption of a 24 -h process.

These values confirm the results obtained in other studies, where the water absorption in the first $10 \mathrm{~min}$ exceeds $75 \%$ of the water absorbed after $24 \mathrm{~h}$ of saturation.

\subsection{Correlation between the composition of the aggregate and soluble sulphates content}

One of the materials quantified in the composition test is the gypsum $\left(\mathrm{SO}_{4} \mathrm{Ca}: 2 \mathrm{H}_{2} \mathrm{O}\right)$. This material is found in large quantities in recycled aggregates coming from C\&DW without selection at source. From the total of 35 recycled aggregates included in this study, 9 presented more than $2 \%$ of gypsum, which can be identified throughout the visual analysis of the composition, this representing a $25,7 \%$ of the materials.

Correlation between gypsum content and sulphates soluble in acid has also been studied (Fig. 9), obtaining a polynomial correlation between both properties, with a correlation coefficient $R^{2}=0.71$. By using this regression, we could reject recycled aggregates with a gypsum content higher than $1.67 \%$, due to the fact that Spanish and European specification for soluble sulphates in acid is $0.8 \%$ in aggregates used in the production of concrete.

\section{Conclusions}

- In this work, 35 mixed recycled coarse aggregates that came from $11 \mathrm{C} \& D W$ treatment plants of different regions of Spain were characterised, in order to add some criterions of acceptance or rejection in the recycling plant for their application in concrete.

- For aggregate characterisation, composition tests of aggregate, absorption, density, sulphur contents and soluble sulphates in acid were carried out. These tests were selected since they are of great importance in this type of recycled aggregates.

- Depending on the content of ceramic and concrete particles, the following classification of the recycled aggregates is proposed Concrete recycled aggregate - CRA - concrete content $\geqslant 90 \%$. Mixed recycled aggregates - MixRA - ceramic content $\leqslant 30 \%$ and $>10 \%$.

Ceramic recycled aggregates - CerRA - ceramic content $>30 \%$.

- From correlations obtained between the different properties (Figs. 2-8), we can define the usual ranges of density and water absorption for each recycled aggregate category, as well as the limits recommended for the concrete content (Table 3).

- The high absorption of the recycled aggregate causes a decrease of concrete workability that can be compensated by means of recycled aggregate pre-soaking. Nevertheless, the low density of the ceramic aggregates reduces the density of concrete made with mixed recycled aggregate.

- According to Spanish standardization, soluble sulphate content of recycled aggregates is limited to $0.8 \%$. Gypsum content is directly related to this property. On the other hand, recycled aggregate samples with a gypsum content higher than $1.67 \%$, present a sulphate content higher than $0.8 \%$ in most cases. Therefore, in order to establish a criterion of acceptance/rejection of the recycled aggregates in the recycling plant, the content of gypsum obtained in the composition test should be limited to $1.5 \%$.

This study has established a variety of recommendations for the use of gypsum content, water absorption and saturated surface dry density of different categories of coarse recycled aggregates, in concrete production. It might be quite useful to make up a composition test [5] so as to obtain gypsum and ceramic content. This test can be easily done in the C\&DW recycling plant, and it will provide with a criterion to accept or reject recycled aggregates samples for different applications. The CRA (recycled concrete aggregate) category could be used for structural concrete production, whereas the mixed recycled aggregates (MixRA) category seems to be more appropriate for non-structural concrete. In addition, studies about the applications of aggregate ceramic recycled aggregate (CerRA) should be carried out as well.

\section{Acknowledgements}

The results shown in this article are from the research work conducted within the framework of the CLEAM CENIT project. This was carries out by the Centro para el Desarrollo Tecnológico e Industrial (CDTI) through the CENIT programme. The results are therefore the exclusive property of the companies that promoted the project, namely A.I.E. CLEAM-CENIT.

\section{References}

[1] EHE-08 - Spanish instruction for structural concrete, Ministry of Public Works, August-08 [in Spanish].

[2] BS 8500-2:2002: Concrete-complementary british standard to BS EN 206-1. Part 2: specification for constituent materials and concrete. 
[3] RILEM (international union of testing and research laboratories for materials and structures): specifications for concrete with recycled aggregates. Mater Struct 1994; (27); 557-9.

[4] DIN 4226-100, mineral aggregates for concrete and mortar - part. 100 recycled aggregates; 2000 [German].

[5] Brito J, Pereira AS, Correia JR. Mechanical behaviour of non-structura concrete made with recycled ceramic aggregates. Cem Concr Compos 2005 27:429-33.

[6] Angulo SC, Carrijo PM, Figueiredo AD, Chaves AP, John VM. On the classification of mixed construction and demolition waste aggregate by porosity and its impact on the mechanical performance of concrete S.C.. Mater Struct 2010;43:519-28.

[7] De Jong TPR, Fabrizi L, Kuilman W. Dry density separation of mixed construction and demolition waste. Faculty of Civil Engineering and Geosciences, Department of Geotechnology, The Netherlands.

[8] RILEM "recycled aggregates and recycled aggregate concrete. Recycling of demolished concrete and masonry. In: Hasen TC, editor. RILEM report 6, 1 st ed. E\&FN Spon, 2-6 Boundary Row, London SE $18 \mathrm{HN} ; 1992$.

[9] Huang Baoshan, Shu Xiang, Burdette EG. Mechanical properties of concrete containing recycled asphalt pavements. Mag Concr Res 2006;58(5):313-20.

[10] Evangelista L, De Brito J. State-of-the-art on the use of fine recycled aggregates in concrete production. In: Conference on the use of recycled materials in building and structures. 9-11 November 2004. Barcelona, Spain.

[11] Cachim PB. Mechanical properties of brick aggregate concrete. Constr Build Mater 2009;23:1292-7.
[12] Guerra I, Vivar I, Llamas B, Juan A, Moran J. Eco-efficient concretes: the effects of using recycled ceramic material from sanitary installations on the mechanical properties of concrete. Waste Manage 2009;29:643-6.

[13] Binici $H$. Effect of crushed ceramic and basaltic pumice as fine aggregates on concrete mortars properties. Constr Build Mater 2007:21:1191-7.

[14] Specification LNEC 471. Guidance for the use of coarse recycled aggregates in concrete of hydraulic binds. MOPTC - Civil Engineering National Laboratory [in Portuguese].

[15] Pr-EN Part 11: classification test for the constituents of coarse recycled aggregate. European Standard Norm; 2002

[16] UNE-EN 1097-6 - tests for mechanical and physical properties of aggregates. Part 6: determination of particle density and water absorption; 2000.

[17] UNE-EN 1744-1 - tests for chemical properties of the aggregates - chemical analysis.

[18] Gómez-Soberón ]. Porosity of recycled concrete with substitution of recycled concrete aggregate: an experimental study. Cem Concr Res 2002;32:1301-11.

[19] Katz A. Properties of concrete made with recycled aggregate from partially hydrated old concrete. Cem Concr Res 2003;33:703-11.

[20] Rao A, Jha KN, Misra S. Use of aggregates from recycled construction and demolition waste in concrete. Resour Conserv Recy 2007;50:71-81.

[21] Sánchez M, Alaejos P. Influence of attached mortar content on the properties of recycled concrete aggregate. In: RILEM proceedings PRO 40 - international RILEM conference on the use of recycled materials in buildings and structures, vol. 1 ; 2004. p. 536-42.

[22] DIN 4226-1:2000: concrete aggregate. 